\title{
Religion, contact and ambivalent attitudes towards the rights of gays and lesbians in Barbados
}

\author{
Mahalia Jackman
}

Department of Economics, University of the West Indies, Cave Hill Campus, Barbados, Email:mahalia.jackman@cavehill.uwi.edu or mahalia.jackman@outlook.com

This is a pre-published draft. A revised version of this paper has been published in the Journal of Homosexuality and available at Taylor and Francis via https://doi.org/10.1080/00918369.2019.1601434. Please cite the published version

\begin{abstract}
Over 70 countries in the world currently carry anti-gay laws, among which is Barbados, a small English-speaking Caribbean island. This study evaluates whether heterosexuals in Barbados are consistent or ambivalent in their attitudes towards anti-gay law reform and the extent to which competing messages from interpersonal contact and religion affect ambivalence. The analysis revealed that a majority of heterosexuals hold ambivalent attitudes about gay and lesbian rights. Moreover, results from a multinomial logistic regression imply that Barbadians whose views on sexuality were theologically based were less likely to support restrictions on same-sex intimacy when they have a close relationship with a gay man or lesbian. However, this decline in support for the laws brought about by meaningful contact did not translate to support for gay and lesbian rights among the religiously inclined. Rather, it manifested itself as a state of attitudinal ambivalence.
\end{abstract}

Keywords: gays; lesbians, rights, ambivalence, attitudes, religion, contact, LGBT, Barbados 


\section{Introduction}

Currently, one of the most contested global issues concerns the rights of same-sex couples. In the Global North, the fight for the legality of same-sex intimacy has largely been won, and current discourse on rights for sexual minorities focus on marital and adoption rights.

However, the advancement of the rights of sexual minorities in other countries significantly lags that of the Global North. As at 2017, over 70 countries carry laws that criminalised private consensual same-sex intimate acts (Carroll \& Mendos, 2017), among which is the small English-speaking Caribbean state under review in this paper: Barbados. In Barbados, same-sex relations are not legally recognised; there are no laws prohibiting discrimination on the basis of sexual orientation; and finally, Barbados carries laws that define the type of sex that is appropriate between consenting adults (Alexander, 1994). A common view is that the current laws are anchored by public disapproval of sexual minorities (Commonwealth Human Rights Initiative, 2011). However, without empirical evidence to the contrary, it seems naïve to assume that there is a uniform stance on sexuality in Barbados. Many social and political psychologists have moved away from the traditional view that attitudes are univalent, and it is generally accepted that many persons may feel ambivalent about an issue (Conner \& Armitage, 2008; Huckfeldt \& Sprague, 2000)

The term ambivalence is often used to describe the expression of conflicting viewpoints or simultaneously holding positive and negative attitudes towards an issue (Hoffarth \& Hodson, 2016). The literature suggests that there are a number of antecedents of ambivalence, among which is the fact that social reasoning is not determined by a single stimulus but is developed from multiple domains such as one's social networks and nuggets of one's core beliefs (Heinze \& Horn, 2009; Huckfeldt \& Sprague, 2000). Hence, we often arrive at a position on an issue through different social and cognitive processes. For a subset of individuals, all these factors may point in the same direction, making it easy for them to take a firm position on an issue. However, many other individuals receive messages from both sides of the debate, and so, may end up in a state of attitudinal ambivalence (Huckfeldt $\&$ Sprague, 2000). Policies regulating same-sex relationships, the case I examine here, is among the chief issues that individuals may receive competing messages about from their evaluative predispositions. These cross-pressures, in turn, could lead to mixed feelings about gay and lesbian rights. In this paper, I focus on the cross-pressures coming from interpersonal contact and religion. 
When thinking about extending basic rights to same-sex couples, individuals often draw on teachings from their religion. Many religious institutions preach against same-sex intimacy (Olson, Cadge, \& Harrison, 2006), which is not surprising as many religious texts have passages that are viewed as criticisms of same-sex intimacy (Comstock, 1991; Siker, 2007). Persons may also base their opinions on informational assumptions (Heinze \& Horn, 2009), for instance, the information gained via interpersonal contact with gays and lesbians (Smith, Axelton, \& Saucier, 2009). Personally knowing someone who identifies as "gay" often breeds empathy towards and trust of gay men and lesbians (Herek \& Capitanio, 1996). Receiving competing messages from these two evaluative predispositions could lead to mixed feelings about lesbian and gay rights. In fact, there is research to support this line of thinking. Garner (2013) showcases that there is significant variation in sexual prejudice among Evangelical Christians when these individuals personally know a sexual minority. Garner (2013) proposes that this pronounced variability in attitudes reflects the conflict between religious opposition towards the rights of gays and lesbians and the prejudice reducing effects of interpersonal contact. Against this backdrop, the current study seeks to determine the extent to which citizens of Barbados support the anti-gay laws. It attempts to answer the following research questions:

1. Are attitudes towards the anti-gay laws consistent or do individuals in Barbados hold conflicting feelings about the anti-gay laws?

2. If inconsistent, to what extent is attitudinal ambivalence influenced by competing messages from interpersonal contact with gays and lesbians and religious values?

The findings from this study should be particularly useful to Barbados. In the last decade, the anti-gay laws of Barbados have received considerable international attention, and public officials in the country have come under fire for the continued criminalisation of private sexual acts (Jackman, 2016). In spite of international criticism, Barbados has chosen to keep the laws on the books. The choice to put international relations at risk suggests that strong domestic social forces could be at play. In fact, a common narrative in the literature on sexual prejudice in the Caribbean is that Caribbean citizens are largely intolerant of gay men and lesbians (Gromer, Campbell, Gomory, \& Maynard, 2013). If policymakers believe that Barbadians are strongly against law reform, they may opt to keep the laws in place to maintain public favour. However, Murray $(2006,2009)$ suggests that the claim that Barbadians are homophobic is both correct and incorrect. Murray believes that Barbadian attitudes towards lesbians and gay men are complex, and not as univalent as the literature would suggest. As such, an understanding of the various dimensions of attitudes in Barbados 
is imperative, as this could aid policymakers and activists understand how the general public would react to policy intervention.

Notwithstanding the obvious benefits for Barbados, the study also has relevance outside of the Barbadian context. First, this paper focuses on ambivalence in attitudes towards the human rights of same-sex couples. While much is known about the factors influencing the approval/disapproval of same-sex intimacy, not many studies have exclusively focused on attitudinal ambivalence (Hoffarth \& Hodson, 2014). The study thus adds to the sparse body of knowledge on the factors influencing ambivalence towards samesex relationships. Second, bans on private sexual acts are currently an important human rights issue, one that has captured the attention of key international bodies, economic stakeholders and governments around the world. Theoretically, the fight to eradicate the bans on same-sex intimacy is at the global level. This international humanitarian effort requires an understanding of sexual prejudice in every country (Lin, Button, Su, \& Chen, 2016) — or, at the very least, an understanding of attitudes across a variety of cultural contexts. Yet, to date, most national-level studies on opinions on the rights of sexual minorities tend to focus on a subset of Western countries (mainly the US and Western Europe), where the fight for the legality of same-sex sexual acts has already been won (Jackman, 2016). The lack of studies on this issue outside North America and Western Europe limits our understanding of anti-gay attitudes, which in turn is an impediment to collective action to reduce state-sponsored discrimination against gay men and lesbians at the global level. By focusing on Barbados, this study adds to the sparse body of work examining sexual prejudice in countries that are not classified as developed and/or still criminalise same-sex intimacy. While the findings of this study cannot be assumed to be universal for countries with anti-gay laws, it does seem plausible that better parallels can be made with Barbados than countries in the West, who, in comparison, currently hold a much more liberal stance on same-sex intimacy.

\section{Background}

\section{The Socio-Legal Situation of LGBT persons in Barbados}

Barbados is a small English-speaking Caribbean island. According to the latest census (Barbados Statistical Service, 2013), the island has a population of 277,821 persons, predominantly of African descent (over 90\%). Barbados is currently classified as a highincome country (World Bank, 2018) with very high levels of human development (United Nations Development Programme, 2018) and high scores in terms of political rights and civil 
liberties (Freedom House, 2017). In spite of these achievements, conditions remain difficult for same-sex couples: Barbados still carries anti-gay laws, with some of the harshest penalties in the Western hemisphere.

The laws of Barbados are often classified as part of the dark legacy of British imperialism (Jackman, 2016, 2017). In 1553, Britain criminalised the act of "buggery" (that is, anal sex) under the 1553 Buggery Act $^{1}$. The crime of buggery was punishable by death until the enactment of the Offences against the Person Act 1861 (West \& Woelke, 2002), which lowered the punishment for the crime of "buggery" to life imprisonment, or a minimum of ten years. While the early British laws criminalised penetrative sex between men, sex between men was not the sole target of the law. It was also an offence to commit an act of 'buggery' with a female or with any animal. The first laws to explicitly target intimacy between men came in 1885. Section 11 of the 1885 Criminal Law Amendment Act said:

"Any male person who, in public or private, commits or is a party to the commission
of, or procures or attempts to procure the commission by any male person of, any act
of gross indecency with another male person, shall be guilty of a misdemeanour, and
being convicted thereof shall be liable at the discretion of the Court to be imprisoned
for any term not exceeding two years, with or without hard labour"

Though the 1885 laws gave no formal definition of what constituted an act of "gross indecency" between men, acts of gross indecency have often been interpreted as all intimate acts between men other than anal sex (Waites, 1998).

Barbados, like many other British colonies, was subjected to its colonial master's antisodomy provisions. Today, the laws are seen as representative of Caribbean culture (Jackman, 2016), strengthened through local mores, values and socialization (Beck et al., 2017). Since gaining independence from Britain, legislators in Barbados have revised several laws governing sex (Robinson, 2009) but opted to keep laws that largely resemble those implemented during colonialism. Section 9 of Chapter 154 of Barbados' 1992 Sexual Offences Act states that

\footnotetext{
"Any person who commits buggery is guilty of an offence and is liable on conviction on indictment to imprisonment for life."
}

The country also criminalises acts of "serious indecency", as stated in Section 12 of Chapter 154 of Barbados' 1992 Sexual Offences Act:

\footnotetext{
${ }^{1}$ The Buggery Act was repealed that same year (in 1553) on the accession of Queen Mary, but re-enacted by Queen Elizabeth I in 1563.
} 
"A person who commits an act of serious indecency on or towards another or incites another to commit that act with the person or with another person is guilty of an offence and, if committed on or towards a person 16 years of age or more or if the person incited is of 16 years of age or more, is liable on conviction to imprisonment for a term of 10 years."

As can be seen above, the laws do not differentiate between acts done in private or public, or whether acts or consensual or forced. The laws are also applicable to all persons regardless of gender or sexual orientation or orifice(s) used. Nonetheless, the laws are often misinterpreted as applying to individuals of a specific sexual orientation and gender identity, rather than sexual acts (AIDS-Free World, 2010; Gaskins, 2013). In Barbados, buggery is synonymous with same-sex intimacy (Griffith \& Wickham, 2018), and Barbadians tend to use the terms "decriminalisation of buggery" and "decriminalisation of homosexuality" interchangeably (Abramschmitt, 2008). At this juncture, I should point out that these laws are not currently used to target private consensual acts (Jackman 2016). However, the lack of formal enforcement does not mean that these laws are harmless. One must bear in mind that laws are part of a larger socio-political process, and so they help shape norms by prefiguring values, prejudices and interests (Tankard \& Paluck, 2017; van den Akker, van der Ploeg, \& Scheepers, 2013). The anti-gay laws in Barbados thus create the presumption that gays and lesbians are criminals and legitimize sexual prejudice.

In the last few years, state-sponsored homophobia in Barbados has received considerable international attention. For instance, the International Gay and Lesbian Human Rights Commission and the Commonwealth Human Rights Initiative have both accused Barbadian public officials of failing in their obligation to protect fundamental human rights (Commonwealth Human Rights Initiative, 2011; International \& Gay and Lesbian Human Rights Commission 2011, 2012). Barbados is a signatory to various human rights documents (such as the International Covenant on Civil and Political Rights and the International Covenant on Economic, Social and Cultural Rights) whose treaty bodies stipulate the right to equality, non-discrimination and privacy for all persons. The Joint United Nations Program on HIV/AIDS (UNAIDS) has also called for the overturning of the country's anti-gay laws, arguing that in addition to violating human rights, they also have a negative impact on HIV/AIDS prevention and access to healthcare (UNAIDS, 2010).

Statements made by some public officials in Barbados suggest that public opinion of sexual minorities serves as a barrier to law reform. For example, in response to recommendations from the United Nations (UN) Human Rights Committee to remove the anti-gay laws, the Government of Barbados noted that: 


\begin{abstract}
"Barbados cannot accept at this time, the recommendation to decriminalize such sexual acts between consenting adults of the same sex. Decriminalization of sexual acts between adults of the same sex has not received the consensus of religious denominations or the public of Barbados as a whole. In fact, significant sections of the community are opposed to such decriminalization...It must be noted that Barbados is a heavily religious society, and there is a significant lobby by the church on such issues." (UN Human Rights Committee, 2009)
\end{abstract}

A key observation is that government officials in Barbados cite the church as a strong veto player in the politics of lesbian and gay rights. This is in line with the general theme on work published in the Caribbean, which suggests that sexual prejudice is largely driven by conservative Christian beliefs (Cowell, 2011; Gutzmore, 2004; Maiorana, Rebchook, Kassie, \& Myers, 2013).

Census data indicates that roughly $79.4 \%$ of the Barbadian population claim a religious identity, and Christianity holds the largest number of adherents (Barbados Statistical Service, 2013). Specifically, approximately 76 percent of Barbadians nominate Christianity as their religion, meaning that over 95 percent of the religiously affiliated are Christian. Opposition from religious interest groups, coupled with public subscriptions to conservative Christian views about sexual orientation, could make the retrenchment of these laws difficult. Policymakers have thus opted for the 'wait until society evolves' approach to law reform. Interestingly, recent work by Griffith and Wickham (2018) suggests that Barbadian attitudes are evolving. Using nationally representative data, the authors report that in 2013, 67.3 percent of Barbadians stated that they accepted or tolerated lesbians and gay men, compared with 62.9 percent in 2004. Griffith and Wickham also report statistically significant declines in social distance: fewer individuals were willing to reject friends, family, children, employees, employers, teachers, and/or public officials who identified as "gay". However, the authors note that though acceptance is on the rise, a majority of persons (over 50\%) still want the buggery laws on the books.

The findings by Griffith and Wickham (2018) show that in spite of the charged sociolegal environment, the situation is not monolithic and attitudes towards the LGBT community may not be as stark as suggested by the political elites. There is even anecdotal evidence in line with this view. For example, in Barbados, a well-known self-identified transgender woman has won the coveted title of Best Flag Person at the Grand Kadooment ${ }^{2}$ on numerous occasions (Murray, 2009), and currently holds the record for the most wins (twenty as at June

\footnotetext{
${ }^{2}$ Kadooment is the grand finale of Barbados' largest annual national festival 'Crop Over'. It is a carnival parade and features several bands whose members, 'the revellers', make their way down the streets dressed in elaborate costumes and dancing to soca and/or calypso music. The Crop Over season normally begins in May/June and ends on Kadooment Day, which is the first Monday in August.
} 
2018). More than this, in February 2018, the Easy magazine (a subsection of one of Barbados' leading newspapers "The Nation") featured a same-sex couple (women) on the cover and also featured a multi-page spread where the couple spoke candidly about their relationship. While the evidence to date does not necessarily mean that this society fully accepts members of the LGBT community, it does call depictions of a uniform anti-LGBT stance into question. One cannot help but wonder: to what extent do citizens of Barbados actually fully support the laws currently on the books? More than this, are individuals consistent in their views? In what follows, I evaluate the prevalence of support for the antigay laws of Barbados.

\section{Previous Research and Research Hypothesis}

As noted in the introductory remarks, very few studies have focused on how conflicting messages from one's evaluative predispositions influence ambivalence towards same-sex couples and their respective rights. Recent works by Craig, Martinez, \& Kane (2005), Bean \& Martinez (2014) and Steele \& Helmuth (2018) have sought to remedy this problem. Analysing a state-wide telephone survey of residents in Florida, Craig, Martinez, \& Kane (2005) found that many individuals were ambivalent about issues related to gay and lesbian rights and that ambivalence was related to conflict among citizen's underlying core values, chiefly, egalitarianism and traditional marriage roles. Bean \& Martinez's (2014) study focused on Evangelicals in the US. Using data from the 2010 Baylor religion survey, Bean and Martinez opine that institutionalised sources of ambivalence have generated tensions among Evangelicals. Specifically, the authors found that ambivalent Evangelicals were more likely to be politically liberal and more likely to believe that same-sex attraction is innate than Evangelicals who consistently oppose extending rights to same-sex couples. Finally, Steele \& Helmuth (2018) used data from the General Social Survey to analyse how ten indicators of socially structured conflicts (that is, conflicting norms associated with institutionally and socially influenced status positions) affect attitudinal ambivalence in the US. Steele \& Helmuth found that the more structural conflicts a person experiences, the more likely they are to express ambivalent attitudes. The current study builds on the aforementioned empirical work on the determinants of ambivalent attitudes towards extending rights of same-sex couples - this time around, focusing on a non-US context and the role of religion and interpersonal contact. 
As is well documented, religion and interpersonal contact are key determinants of attitudes towards policies regulating same-sex intimacy. In his classic functionalist analysis of prejudice against gay men and lesbians, Gregory Herek (Herek, 1991) suggests that sexual prejudice may serve a value-expressive function, allowing people to express values that are important to them. For example, some individuals may express sexual prejudice as a means of affirming their religious beliefs, teachings and values (Kuhar, 2013). Some religious individuals thus argue that they cannot support laws extending civil rights to gay men and lesbians as this would violate their religious beliefs, teachings and values (Herek, 1991). It is therefore not surprising that a principal justification for hostility towards lesbians and gays men is religious morality (Herek, 1991). One of the most consistent findings in the academic literature is that religious individuals tend to be less accepting of gays and lesbians than the religiously unaffiliated and are also less supportive of their rights (Hayes \& Dowds, 2015; Walls, 2010; Whitehead \& Perry, 2016).

On the other hand, interpersonal contact with gays and lesbians is believed to reduce sexual prejudice, and this logic stems from Allport's intergroup contact theory (Allport, 1954). The basic idea is that by interacting with members of the out-group, the in-group learns about the out-group, and this new information may challenge stereotypes and overgeneralised information that can influence attitudes (Skipworth, Garner, \& Dettrey, 2010). With less stereotypical information, direct attitudes towards the out-group may become more tolerant. Recently, a significant amount of research has shown that heterosexuals who have interpersonal contact with gay men and lesbians tend to express more positive attitudes towards this group than individuals with no contact (Becker, 2012; Herek \& Capitanio, 1996; Herek \& Glunt, 1993; West \& Hewstone, 2012). There is also evidence of an intimacy effect - the closer the connection, the greater the impact ( Becker, 2012; Becker \& Scheufele, 2009). Essentially, close relationships with sexual minorities allow others to gain intimate information, and this personalisation is believed to aid in reducing prejudice (Herek \& Capitanio, 1996).

Given this study's concept of ambivalence as expressing conflicting views towards a single issue, the main research hypothesis of this study is that the conflicting messages from interpersonal contact and one's religion makes holding a univalent stance on the anti-gay laws difficult. Specifically, persons with a close contact that identifies as gay or lesbian, but whose views on sexuality are theologically based will be more ambivalent about the criminalisation of consensual same-sex acts than their equivalent with no contact. 


\section{Methods}

\section{Participants and recruitment}

The study utilised secondary data obtained from the 2013 Caribbean Development Research Services (CADRES) 'Attitudes towards homosexuals' survey. The initial database consisted of 830 Barbadian adults (50.2\% female, $49.8 \%$ male). As I focus on heterosexual ambivalence, individuals who identified as gay/lesbian (22 persons) and bisexual (30 persons) were removed from the sample. A large segment of persons (72) chose the option 'I prefer not to say' when asked about their sexual orientation, and 17 persons did not provide a response. As the orientation of the latter subsets of individuals were unclear, I opted to remove them from the analysis. This initially reduced the sample size to 689 individuals. The study also focuses on ambivalence in the form of conflicting attitudes towards the laws, defined as persons who support law reform in one dimension, but are against law reform in another dimension. The survey items capturing support for the laws provided survey participants with three response options: "Yes", "No" and "Unsure/Prefer not to say". Persons who chose "Unsure/Prefer not to say" were removed from the analytical sample as it would be difficult to discern between those who chose this option due to internal conflict, those who chose this option as they were indifferent and those who had an opinion but preferred not to state it. List-wise removal of the "Unsure/Prefer not to say" responses and missing observations across the various survey items resulted in an analytical sample of 397 individuals.

According to the CADRES reports (Caribbean Development Research Services, $2013)^{3}$, participants were recruited using stratified random sampling techniques, with the primary strata being age and gender. Interviewers were randomly assigned to areas associated with the polling districts in Barbados. The polling districts are almost equal subdivisions of constituencies, which are normally used for electoral purposes. The polling districts were numbered, allowing for a random selection of specific divisions, which CADRES then translated into geographical districts. In each instance, interviewers selected 12, 24, 36 or 48 households in a random manner ( 1 in 3), and conducted interviews at each of the 12, 24, 36 or 48 households. One respondent in each of these households became the interviewee. The survey was largely administered via face-to-face interviews, though interviewers complied with requests from respondents to complete the questionnaire on their own. The section of the survey that asked about sexual orientation and interpersonal contact with lesbians and gay

${ }^{3}$ CADRES did not provide information about the response rates. 
men was set aside for interviewees to answer on their own, as CADRES viewed these as confidential issues. Interviewers were advised to only complete this section of the form if requested by the respondent.

\section{Measures}

Ambivalence towards the rights of gays and lesbians

The literature suggests two ways of measuring ambivalence (Hoffarth \& Hodson, 2016). The first is subjective ambivalence, which is measured by asking participants to indicate their ambivalence (that is, whether they feel torn or conflicted on an issue). The second measure is that of calculated ambivalence, where a researcher constructs ambivalence from using separate self- reported attitudes. The second measure is used in this study.

The following four questions from the CADRES surveys were used to construct a measure ambivalence towards the current laws:

- "Presently, the laws of Barbados outlaw the act of Buggery/Sodomy, whether between two men or a man and a woman regardless of whether the act is in public or private, consensual or forced. Do you generally support the maintenance of this law?"

- "Currently, the laws of Barbados with respect to Buggery/Sodomy are NOT being enforced (except in instances of forced sex/rape). Do you think that the state should enforce these laws by investigating and prosecuting persons who engage in these acts (by consent)?”

- "Do you think that the laws of Barbados should penalise two men for having 'sexual intercourse' in private?"

- "Do you think that the laws of Barbados should penalise two women for having 'sexual intercourse' in private?"

As mentioned in the participants and recruitment subsection, individuals who opted for "Unsure/Prefer not to say" were removed from the analysis, leaving persons who chose "Yes" or "No" on these four items. Given the categorical nature of these survey items, I constructed a simple 3-category variable to capture the simultaneity of conflicting opinions. The first category captures individuals who consistently oppose law reform, that is, want the buggery/sodomy laws maintained, enforced and believes that two men or women should be penalised for having sex in private; the second category is made of those who consistently 
support law reform; and the final category comprises of persons who are ambivalent (for example, chooses "No" for some aspect(s), but "Yes" for others).

\section{$\underline{\text { Religion }}$}

Unfortunately, the CADRES survey did not include popular measures of religiosity, such as frequency of church attendance or the importance of religion to one's life. However, one of the survey's items could be used to capture the impact of religious information on attitudes towards same-sex relationships. Respondents were asked to state the source of their views on sexuality. This variable was dichotomized, with a value of "1" if the respondent noted that their main source of views on sexuality came from religious sources; 0 otherwise.

\section{$\underline{\text { Interpersonal Contact }}$}

The interpersonal contact variable was derived from the survey item that asked participants whether or not they had any friends who identify as gay. This variable was coded as a binary variable, which took on a value of " 1 " if the individuals" response was "Yes" and "0" otherwise.

\section{Control Variables}

The study also controlled for the impact of age, gender, education and feelings about sexual minorities. These controls were included because of their presumed correlations with sexual prejudice (Craig, Martinez, \& Kane, 2005; Steele \& Helmuth, 2018). These variables were all categorical, largely reflecting the structure of the CADRES survey items. Specifically, the gender variable was in binary form, with men serving as the reference category. Age was recorded using three distinct age groups: (1) 18-30 (contrast); (2) 31-50 and (3) 51 and over. Education was divided into three categories: (1) compulsory schooling (that is, primary/secondary education); (2) post-secondary education; and (3) tertiary education, where the base category is compulsory schooling. Finally, attitudes towards lesbian and gay male sexual orientation were measured using responses to the following survey item "What word best describes your attitude towards homosexuals?". The response options were: (1) hate (reference category); (2) tolerate; (3) accept; and (4) don't know. Table 1 provides some descriptive statistics for all the independent variables used in the study control variables. 


\section{Results}

Support for the anti-gay laws

Figure 1 presents the distribution of the survey items used to construct the dependent variable. In each case, a majority of the final sample supported the maintenance of the antigay laws as is (74 per cent) and their enforcement (67 per cent). Public support for the maintenance and enforcement appears to echo the political narrative that Barbadians do not support law reform. However, Figure 1 also shows evidence of mixed attitudes. While a majority of the sample supported the maintenance and enforcement of the laws, they did not support the penalisation of sex between persons of the same sex, with approximately 59 per cent of the analytical sample opposing penalising two men for having sex in private and 65 per cent against penalising sex between women.

Turning to the constructed measure of ambivalence (Figure 2), only 27 per cent of the sample consistently supported having the laws on the books, 15 per cent of the sample were consistently against the anti-gay laws, while a majority of the sample (57 per cent) gave conflicting responses. The analysis thus far indicates that attitudes towards law reform in Barbados are not set in black and white. Rather, there is a large grey area, as a significant subset of Barbadian nationals hold seemingly conflicting attitudes about the current laws. Having determined that a significant share of persons hold mix views about the current laws, an obvious question that arises is: who is likely to have these mixed feelings? In this study, I posit that the mixed views on these laws stem from conflicting predispositions, one of which is the cross-pressures of religion and interpersonal contact with gays and lesbians. This is evaluated using multinomial models in the next subsection.

\section{Multinomial regression results}

To investigate the role of contact and religion in influencing attitudinal ambivalence, ambivalence was estimated as a function of religion, contact and the control variables via a multinomial logistic regression. I opt to use a multinomial logistic regression model as the dependent variable (the ambivalence construct) consists of three unordered categories. Ambivalent attitudes serve as the reference category.

The estimated results from the multinomial model are presented in Table 2. Individuals whose views on sexuality have a theological base were more likely to consistently support the laws than be ambivalent $(p<0.001)$. Meanwhile, having friends that identify as gay or lesbian reduced the likelihood of uniformly supporting the laws 
relative to being ambivalent $(p<0.01)$. With respect to the control variables, women, persons under 31 and those with more positive attitudes towards gay and lesbians were less likely to be opponents of gay and lesbian rights, and more likely to report conflicting views on the issue. The second column of Table 2 shows factors influencing the likelihood that an individual consistently supports gay and lesbian rights relative to being ambivalent. Persons with religiously inspired views on sexuality were less likely than persons with non-religious views to lend their full support to lesbian and gay rights $(p<0.05)$. However, there is no evidence that interpersonal contact influenced the probability of consistently supporting gay and lesbian rights relative to being ambivalent. Further, the only control variable that was statistically significant in this case was feelings towards gays and lesbians, where individuals who reported feelings of tolerance or acceptance towards sexual ministries were more likely to fully support fully support gay and lesbian rights, while those who reported negative feelings towards gays and lesbians were more likely to be ambivalent.

To recap, the main aim of this study was to showcase how conflicting attitudes about anti-gay laws could arise from cross-pressures of information about sexual minorities via interpersonal contact and religion. To complete this task, I augmented the multinomial model with an interaction term of "source of views on religion" and "interpersonal contact" to gain insights on how competing messages influences the conflict. A joint test of significance suggested that the interaction term statistically influences the probability that an individual was in the ambivalent category $\left(\chi^{2}(1)=5.18 ; p<0.05\right)$, as well as the probability that an individual was in the 'consistent support for the laws' category $\left(\chi^{2}(1)=6.85 ; p<0.01\right)$. However, the interaction term had a statistically insignificant impact on the likelihood that an individual supported extending basic rights to gays and lesbians $\left(\chi^{2}(1)=0.00 ; p>\right.$ 0.10). As the interaction terms are not directly interpretable, I used effect plots in order to assess their substantive effects. Effect plots allow us to visualise the marginal effects of variables included in the multiplicative interaction term. This was done using the "marginsplot" post-estimation command in Stata. The effect plots for the interactions that were significantly significant are given in Figure 3. The figure shows that religious persons with social contact with gays and lesbians were less likely to consistently support the laws than those without contact. In line with my a-priori expectations, the results suggest that those whose views on sexuality were shaped by religion but also had gay friends were more likely to be conflicted when it comes to government regulations on same-sex intimate acts. For individuals receiving competing messages from religion and interpersonal contact, the 
predicted probability of reporting conflicting attitudes was 15.6 percentage points greater than persons whose views on sexuality were theologically based but had no friends that identifies as "gay".

\section{Discussion and Concluding Remarks}

Barbados currently carries laws that not only discriminate against same-sex couples, with maximum penalties ranging from 10 years to life imprisonment. Notwithstanding the obvious problems these laws pose for gays and lesbians living in the country, it should be noted that these laws are currently not used to prosecute persons on the basis of their sexuality. So, if not enforced, why do policymakers opt to maintain the laws? Various statements by political

elites portray Barbadians as largely intolerant of sexual minorities and cite public opinion and religious actors as a significant barrier to the repeal of these laws. Yet, while a common view is that these laws are anchored by public support, very few studies have emerged to empirically test whether the attitudes and behaviours of the general population are actually in line with this view. Against this backdrop, this paper investigated the prevalence of support for anti-gay laws in Barbados.

First, the study looked at the extent to which heterosexuals wanted the current laws maintained/enforced and supported the penalisation of persons of the same-sex engaging in sexual acts in private. There was mixed support for the preservation of anti-gay laws: while the majority stated they wanted the current laws maintained and enforced, only a minority endorsed the state penalising private sex between two persons of the same sex. It is possible that Barbadians may be viewing intimate same-sex acts through two lenses. For instance, when asked 'general' questions about the retention and enforcement of Barbados' anti-gay laws, persons may give a response that reflects their beliefs about or level comfort with gays and lesbians. By reformulating the question and asking about two men or two women engaging in sex in private, the latter two survey items lead respondents to think about the individual (not the act) and to also think about the issue within the context of a government meddling in someone's sex life. Taken together, law support in Barbados appears symbolic: persons view intimacy between persons of the same sex as wrong and believe that laws should be in line with this perspective, but do not actually want persons to be penalised for consensual acts in private.

The finding of mixed views on gay and lesbian rights should be of key interest to advocates on the island. Corrales (2015) points out that in order to obtain change, activists 
would need to (1) operate in countries where courts are progressive, (2) have strong political connections, and (3) frame the issue in a way that resonates with majoritarian sentiments. Focusing on the latter requirement presented by Corrales (2015), the results presented in this study provides some insight on how activists may be able to frame the issue of gay and lesbian rights in a way that appeals to public sentiment. Specifically, the results suggest that when entering into conscience debates about these laws, advocates would be better able to garner support for their removal if they base their arguments on the right of the government to regulate sex between persons in private. However, this alone may not be enough to engender change. Recent work by Jackman (2017) revealed that many residents believe that the current laws are a reasonable expression of Barbados' moral standards (57\%), important from a health perspective (55\%) and protect young persons from abuse (39\%). It is possible that ill-founded fears about what law reform could lead to (e.g. deterioration of public health or an increase in incidents of child abuse) could reduce the willingness to extend basic rights to gays and lesbians. Even though some persons may view the regulation of sex between two persons in private as a gross intrusion of privacy, it may be considered a necessary 'evil' to protect the fabric of Barbadian society. Thus, along with careful framing of their arguments, activists must also work on combating ill-founded beliefs about gays and lesbians, possibly through awareness workshops or campaigns. The logic here is that in light of accurate information about gays and lesbians, persons may no longer perceive them as a threat and may change their attitudes about them.

In the second stage of the study, I evaluated the extent to which conflicting messages from evaluative dispositions could lead to varying attitudes towards lesbian and gay rights in Barbados. Religious individuals with interpersonal contact with sexual minorites were less likely to consistently support the laws than those without contact. However, the interaction of religion and interpersonal contact did not significantly affect the likelihood that an individual consistently supported gay and lesbian rights. Rather, persons who take their cues on sexuality from their religion, but also have a gay/lesbian friend were more likely to be conflicted about the laws. This suggests that while interpersonal contact reduces support for the laws for religiously inclined individuals, it does not fully translate to them lending full support to gay and lesbian rights, but rather leads them to a state of ambivalence. Taken together, while persons do not readily abandon religious teachings, the information gained from meaningful contact may be enough to challenge the rhetoric of religious institutions and to mitigate support for law retention. Another take away from the study is that while Barbadians, in general, have become more tolerant over the last decade (as shown by Griffith 
and Wickham, 2018), some have become supporters of lesbian and gay rights, while others may have moderated their opposition to lesbian and gay rights but remain conflicted about the issue. This lends credence to the view that ambivalence could reflect a transitory stage towards more liberal views on lesbian and gay male sexual orientations (Loftus, 2001) and may even serve as "an indicator of fertile ground for social change" (Steele \& Helmuth, 2018).

While this study sheds some light on support for anti-gay laws in Barbados, it is not without its limitations. First, the literature has identified a set of ideologies (such as gender role ideologies, individualism and authoritarianism) that also affect these attitudes, and, if in conflict, could lead to mixed views about the anti-gay laws. Unfortunately, the CADRES did not include measures that could adequately capture these values, and so could not be included in this study. Secondly, this study primarily focused on what contributes towards public attitudes toward anti-gay laws. However, as alluded to in the Background section of this study, laws are essentially socialising agents, and so, the laws themselves may be impacting on citizen's attitudes, the extent of which could not be captured in this study. Moreover, while public tolerance could engender a climate that would be more receptive to law reform, attitudes by themselves are insufficient to bring about law reform and increase equality. Lax and Philips (2009) find that in addition to public opinion, state adoption of policies affecting lesbians and gay rights in the US was also influenced by government liberalism and interest groups. To complement the work presented here, future studies should undertake empirical analyses of the attitudes/values of policymakers and the main interest groups (i.e. the religious organisations) in Barbados.

Even with the aforementioned limitations, this study makes a significant contribution to the literature. As mentioned previously, much of the empirical work to date focuses on attitudes towards same-sex relationships within the context of Western societies, where the fight for the legality of same-sex intimacy has already been won. Given the mounting global attention towards LGBT rights, particularly the removal of bans on same-sex sexual relations, there is a pressing need to investigate attitudes towards gays and lesbians outside of the Western context. This paper, then, is a step towards narrowing the gap in the aforementioned literature. It is hoped that the results from this study inspire more research on attitudes towards gays and lesbians and their respective rights in other countries with anti-gay laws on the books. The more we know about sexual prejudice, the more likely efficacious programmes and strategies can be developed and implemented to persuade individuals to reject sexual prejudice. 


\section{References}

Abramschmitt, C. (2008). Is Barbados ready for same-sex marriage? Analysis of legal and social constructs. Social and Economic Studies, 61-88.

AIDS-Free World. (2010). The Unnatural Connexion: Creating Social Conflict Through Legal Tools Retrieved from Georgetown, Guyana: http://www.aidsfreeworld.org/OurIssues/Homophobia/The-Unnatural-Connexion.aspx

Alexander, M. J. (1994). Not just (any) body can be a citizen: The politics of law, sexuality and postcoloniality in Trinidad and Tobago and the Bahamas. Feminist Review, 48(1), $5-23$.

Allport, G. W. (1954). The nature of prejudice. New York, US: Addison-Wesley.

Barbados Statistical Service. (2013). 2010 Population and Housing Census Volume 1. Retrieved from Bridgetown, Barbados:

Bean, L., \& Martinez, B. C. (2014). Evangelical ambivalence toward gays and lesbians. Sociology of Religion, 75(3), 395-417.

Beck, E. J., Espinosa, K., Ash, T., Wickham, P., Barrow, C., Massiah, E., . . . Nunez, C. (2017). Attitudes towards homosexuals in seven Caribbean countries: implications for an effective HIV response. AIDS Care, 29(12), 1557-1566.

Becker, A. B. (2012). Determinants of public support for same-sex marriage: Generational cohorts, social contact, and shifting attitudes. International Journal of Public Opinion Research, 24(4), 524-533.

Becker, A. B., \& Scheufele, D. A. (2009). Moral Politicking Public Attitudes toward Gay Marriage in an Election Context. The International Journal of Press/Politics, 14(2), 186-211.

Caribbean Development Research Services. (2013). Attitudes towards homosexuals in Barbados (2013). Retrieved from Caribbean Development Research Services, Barbados:

Carroll, A., \& Mendos, L. R. (2017). State Sponsored Homophobia 2017: A world survey of sexual orientation laws: criminalisation, protection and recognition. Retrieved from Geneva, Switzerland:

Commonwealth Human Rights Initiative. (2011). Criminalised States.

Comstock, G. D. (1991). Violence against lesbians and gay men. New York: Columbia University Press.

Conner, M., \& Armitage, C. J. (2008). Attitudinal ambivalence. In W. D. Carno \& B. Prislin (Eds.), Attitudes and attitude change (pp. 261-286). New York, US: Psychological Press.

Cowell, N. M. (2011). Public Discourse, Popular Culture and Attitudes Towards Homosexuals in Jamaica. Social and Economic Studies, 60(1), 31-60.

Craig, S. C., Martinez, M. D., \& Kane, J. G. (2005). Core values, value conflict, and citizens' ambivalence about gay rights. Political Research Quarterly, 58(1), 5-17.

Freedom House. (2017). Freedom in the World 2017: Populists and Autocrats -The Dual Threat to Global Democracy.

Garner, A. (2013). Ambivalence, the intergroup contact hypothesis, and attitudes about gay rights. Politics \& Policy, 41(2), 241-266.

Gaskins, J. (2013). 'Buggery' and the Commonwealth Caribbean: a comparative examination of the Bahamas, Jamaica, and Trinidad and Tobago In C. Lennox \& M. Waites (Eds.), Human Rights, Sexual Orientation and Gender Identity in The Commonwealth: Struggles for Decriminalisation and Change (pp. 429-454). London: School of Advanced Study, University of London. 
Griffith, A., \& Wickham, P. (2018). Tolerance, Acceptance, or Ambivalence?: Changing Expressions of Attitudes towards Homosexuals in Barbados. Sexuality Research and Social Policy, 1-12.

Gromer, J. M., Campbell, M. H., Gomory, T., \& Maynard, D. M. (2013). Sexual Prejudice Among Barbadian University Students. Journal of Gay \& Lesbian Social Services, 25(4), 399-419.

Gutzmore, C. (2004). Casting the first stone!: Policing of homo/sexuality in Jamaican popular culture. Interventions, 6(1), 118-134.

Hayes, B. C., \& Dowds, L. (2015). Religion and Attitudes Towards Gay Rights in Northern Ireland: The God Gap Revisited. In S. D. Brunn \& D. A. Gibreath (Eds.), The Changing World Religion Map: Sacred Places Identities, Practices and Politics (Vol. XIII, pp. 3321-3340). New York, US: Springer.

Heinze, J. E., \& Horn, S. S. (2009). Intergroup contact and beliefs about homosexuality in adolescence. Journal of Youth and Adolescence, 38(7), 937-951.

Herek, G. M. (1991). Stigma, Prejudice, and Violence Against Lesbians and Gay Men. In J. C. Gonsiorek \& J. D. Weinrich (Eds.), Homosexuality: Research implications for public policy (pp. 60-80). Newbury Park, CA: SAGE.

Herek, G. M., \& Capitanio, J. P. (1996). " Some of my best friends": Intergroup contact, concealable stigma, and heterosexuals' attitudes toward gay men and lesbians. Personality and Social Psychology Bulletin, 22, 412-424.

Herek, G. M., \& Glunt, E. K. (1993). Interpersonal contact and heterosexuals' attitudes toward gay men: Results from a national survey. Journal of Sex Research, 30(3), 239244.

Hobolt, S. B., \& Klemmemsen, R. (2005). Responsive government? Public opinion and government policy preferences in Britain and Denmark. Political Studies, 53(2), 379402.

Hoffarth, M. R., \& Hodson, G. (2014). Is subjective ambivalence toward gays a modern form of bias? Personality and Individual Differences, 69, 75-80.

Hoffarth, M. R., \& Hodson, G. (2016). Ambivalence. Encyclopedia of Personality and Individual Differences, 1-4.

Huckfeldt, R., \& Sprague, J. (2000). Political consequences of inconsistency: The accessibility and stability of abortion attitudes. Political Psychology, 21(1), 57-79.

International, \& Gay and Lesbian Human Rights Commission (2011). Human Rights Violations of Lesbian, Gay, Bisexual, and Transgender (LGBT) People in Jamaica: A Shadow Report. Retrieved from Geneva:

International, \& Gay and Lesbian Human Rights Commission (2012). Human Rights Violations of Lesbian, Bisexual, and Transgender (LBT) People in Guyana: A Shadow Report. Retrieved from New York:

Jackman, M. (2016). They called it the 'abominable crime': an analysis of heterosexual support for anti-gay laws in Barbados, Guyana and Trinidad and Tobago. Sexuality Research and Social Policy, 13(2), 130-141. Retrieved from http://dx.doi.org/10.1007/s13178-015-0209-6. doi:10.1007/s13178-015-0209-6

Jackman, M. (2017). Protecting the fabric of society? Heterosexual views on the usefulness of the anti-gay laws in Barbados, Guyana and Trinidad and Tobago. Culture, health \& sexuality, 19(1), 91-106.

Kuhar, R. (2013). Introduction to the issue:"In the Name of Hate: Homophobia as a Value". Southeastern Europe, 37(1), 1-16.

Lax, J., \& Phillips, J. (2009). Gay Rights in the States: Public Opinion and Policy Responsiveness. American Political Science Review, 103(3), 367-386. 
Lin, K., Button, D. M., Su, M., \& Chen, S. (2016). Chinese College Students' Attitudes Toward Homosexuality: Exploring the Effects of Traditional Culture and Modernizing Factors. Sexuality Research and Social Policy, 13(2), 158-172.

Loftus, J. (2001). America's liberalization in attitudes toward homosexuality, 1973 to 1998. American Sociological Review, 66(5), 762-782.

Maiorana, A., Rebchook, G., Kassie, N., \& Myers, J. J. (2013). On Being Gay in Barbados:"Bullers" and "Battyboys" and their HIV Risk in a Societal Context of Stigma. Journal of Homosexuality, 60(7), 984-1010.

Murray, D. A. (2006). Who's right? Human rights, sexual rights and social change in Barbados. Culture, health \& sexuality, 8(3), 267-281.

Murray, D. A. (2009). Bajan queens, nebulous scenes: Sexual diversity in Barbados. Caribbean Review of Gender Studies, 3, 1-20.

Oldendick, R. W. (2002). The Role of Public Opinion in Policy and Practice. Public Policy \& Practice, 2(1), 30-35.

Olson, L. R., Cadge, W., \& Harrison, J. T. (2006). Religion and Public Opinion about SameSex Marriage. Social Science Quarterly, 87(2), 340-360.

Robinson, T. (2009). Authorized sex: Same-Sex Sexuality and Law in the Caribbean. In C. Barrow, M. d. Bruin, \& R. Carr (Eds.), Sexuality, Social Exclusion and Human Rights: Vulnerability in the Caribbean Context of HIV (pp. 3-22). Kingston, Jamaica: Ian Randle Publishers.

Siker, J. S. (2007). Homosexuality and religion: An encyclopedia: Greenwood Publishing Group.

Skipworth, S. A., Garner, A., \& Dettrey, B. J. (2010). Limitations of the contact hypothesis: Heterogeneity in the contact effect on attitudes toward gay rights. Politics \& Policy, 38(5), 887-906.

Smith, S. J., Axelton, A. M., \& Saucier, D. A. (2009). The effects of contact on sexual prejudice: A meta-analysis. Sex Roles, 61(3-4), 178-191.

Steele, S. M., \& Helmuth, A. S. (2018). Predicting Ambivalence: When Same-Sex Sex Is Only "Sometimes Wrong". Journal of homosexuality, 1-22.

Tankard, M. E., \& Paluck, E. L. (2017). The effect of a Supreme Court decision regarding gay marriage on social norms and personal attitudes. Psychological science, 28(9), 1334-1344.

UN Human Rights Committee. (2009). Consideration of reports submitted by States parties under Article 40 of the Covenant - International Convenant on Civil and Political Rights (Barbados): Information received from Barbados on the implementation of the concluding observations of the Human Rights Committee (CCPR/C/BRB/CO/3). Retrieved from http://www.refworld.org/docid/4a9fb80f2.html:

UNAIDS. (2010). The Status of HIV in the Caribbean. Retrieved from Port of Spain, Trinidad and Tobago:

United Nations Development Programme. (2018). Human Development Report Indices and Indicators: 2018 Statistical Update. Retrieved from New York, USA:

van den Akker, H., van der Ploeg, R., \& Scheepers, P. (2013). Disapproval of homosexuality: Comparative research on individual and national determinants of disapproval of homosexuality in 20 European countries. International Journal of Public Opinion Research, 25(1), 64-86.

Waites, M. (1998). Sexual citizens: legislating the age of consent in Britain. In T. Carver \& V. Mottier (Eds.), Politics of Sexuality: Identity, Gender, Citizenship (pp. 25-36). London, UK: Routledge.

Walls, N. E. (2010). Religion and support for same-sex marriage: Implications from the literature. Journal of Gay \& Lesbian Social Services, 22(1-2), 112-131. 
West, D., \& Woelke, A. (2002). England. In D. J. West \& R. Green (Eds.), Sociolegal control of homosexuality: A multi-nation comparison (pp. 197-220). United States: Springer Science \& Business Media.

West, K., \& Hewstone, M. (2012). Culture and contact in the promotion and reduction of anti-gay prejudice: Evidence from Jamaica and Britain. Journal of Homosexuality, 59(1), 44-66.

Whitehead, A. L., \& Perry, S. L. (2016). Religion and Support for Adoption by Same-Sex Couples The Relative Effects of Religious Tradition, Practices, and Beliefs. Journal of Family Issues, 37(6), 789-813.

World Bank. (2018). World Bank Country and Lending Groups. In: World Bank. 
Table 1: Descriptive statistics for independent variables

\begin{tabular}{|c|c|}
\hline & Frequency (Per cent) \\
\hline \multicolumn{2}{|l|}{ Key independent variables } \\
\hline \multicolumn{2}{|l|}{ Source of Views on Sexuality } \\
\hline Other Sources (base) & $199(50.1 \%)$ \\
\hline Religion & $198(49.9 \%)$ \\
\hline \multicolumn{2}{|l|}{ Interpersonal Contact } \\
\hline Have Gay/lesbian Friends & $179(45.1 \%)$ \\
\hline Other (base) & $218(54.9 \%)$ \\
\hline \multicolumn{2}{|l|}{ Control Variables } \\
\hline \multicolumn{2}{|l|}{ Age } \\
\hline $18-30$ (base) & $129(32.5 \%)$ \\
\hline $31-50$ & $161(40.6 \%)$ \\
\hline Over 50 & $107(27.0 \%)$ \\
\hline \multicolumn{2}{|l|}{ Gender } \\
\hline Men (base) & $209(52.6 \%)$ \\
\hline Women & $188(47.4 \%)$ \\
\hline \multicolumn{2}{|l|}{ Education } \\
\hline Compulsory (base) & $147(37.0 \%)$ \\
\hline Secondary & $134(33.8 \%)$ \\
\hline Tertiary & $116(29.2 \%)$ \\
\hline \multicolumn{2}{|l|}{ Feelings towards homosexuals } \\
\hline Hate (Base) & $93(23.4 \%)$ \\
\hline Tolerate & $166(41.8 \%)$ \\
\hline Accept & $94(23.7 \%)$ \\
\hline Don't Know & $44(11.1 \%)$ \\
\hline
\end{tabular}

Notes: Sample size: 397. Based on estimation sample 
Table 2: Results from Multinomial Logit Regression

\begin{tabular}{l|l|l}
\hline & $\begin{array}{l}\text { Support } \\
\text { Discriminatory } \\
\text { Laws vs } \\
\text { Ambivalence }\end{array}$ & $\begin{array}{l}\text { Support Law } \\
\text { reform vs } \\
\text { Ambivalence }\end{array}$ \\
\hline Religious Sources of Views on Sexuality & $0.984^{* *}(0.268)$ & $-0.825^{*}(0.331)$ \\
Interpersonal Contact & $-0.888^{* *}(0.282)$ & $0.036 \quad(0.335)$
\end{tabular}

\section{Control Variables}

Age (base: 18-30)

31-50

Over 50

Woman

Education (base: compulsory schooling)

Secondary

Tertiary

$$
\begin{array}{lll}
0.717 *(0.314) & -0.270 & (0.363) \\
0.807 *(0.349) & -0.009 & (0.400) \\
& & \\
-0.810 * *(0.262) & -0.284 & (0.318)
\end{array}
$$

$\begin{array}{llll}0.102 & (0.305) & -0.158 & (0.381)\end{array}$

$\begin{array}{llll}0.235 & (0.325) & -0.020 & (0.382)\end{array}$

Feelings towards gays and lesbians (base:

Hate)

$\begin{array}{llllr}\text { Tolerate } & -0.968 * * & (0.316) & 1.837 * & (0.769) \\ \text { Accept } & -0.902 * & (0.413) & 2.998 * * *(0.776) \\ \text { Don't Know } & -0.363 & (0.399) & 1.080 & (0.950)\end{array}$

Notes: (1) Sample size: 397; (2) Log-Likelihood: -323.00; (3) Pseudo R-squared: 0.196; (4) Standard errors in parentheses; and $(5) * * *, * *, *$ and + indicates statistical significance at the $0.1,1,5$ and 10 per cent levels respectively 
Figure 1: Heterosexual support for the anti-gay laws

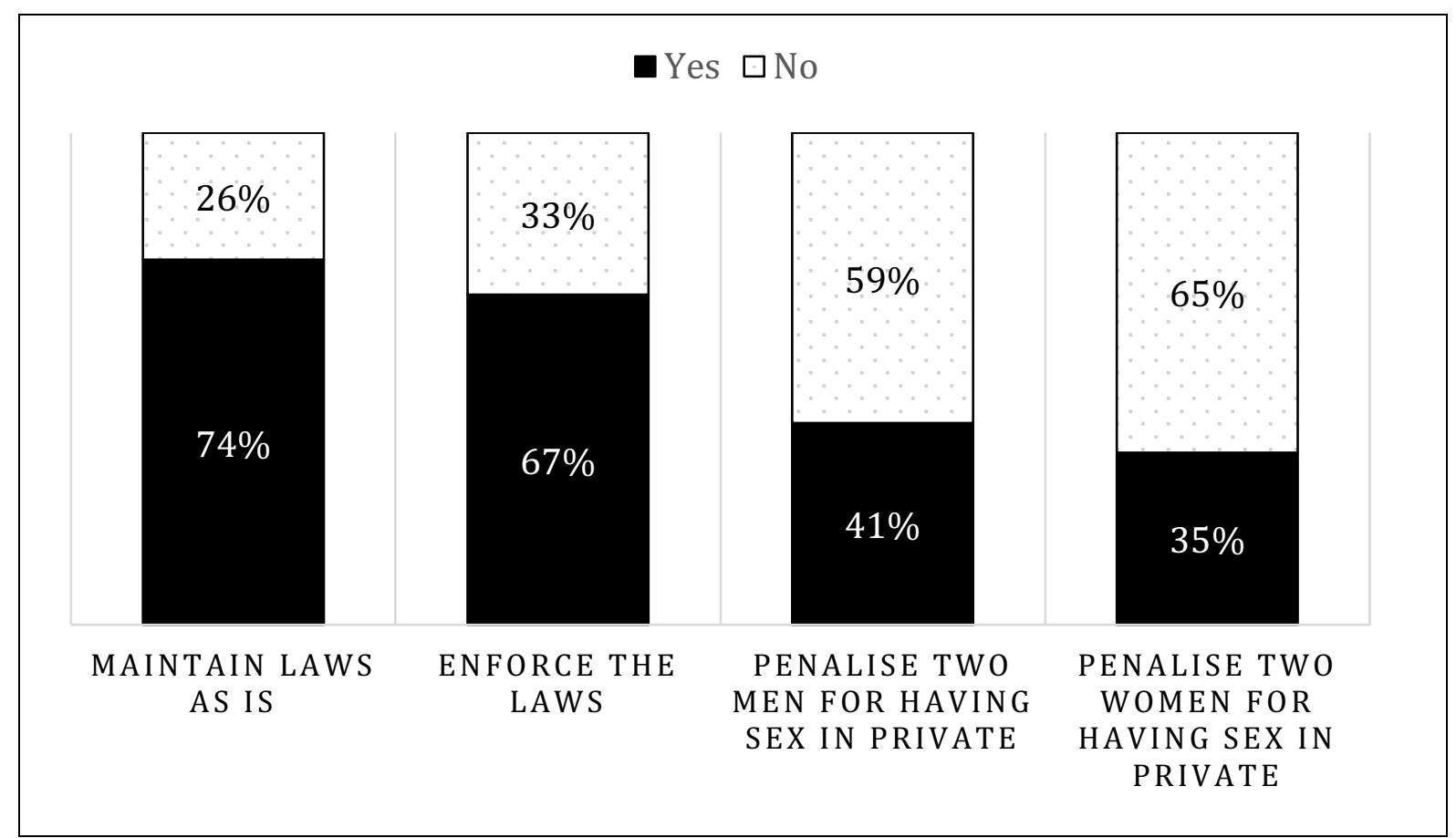

Notes: Sample size: 397. Based on estimation sample 
Figure 2: Consistent and Inconsistent support for the anti-gay laws

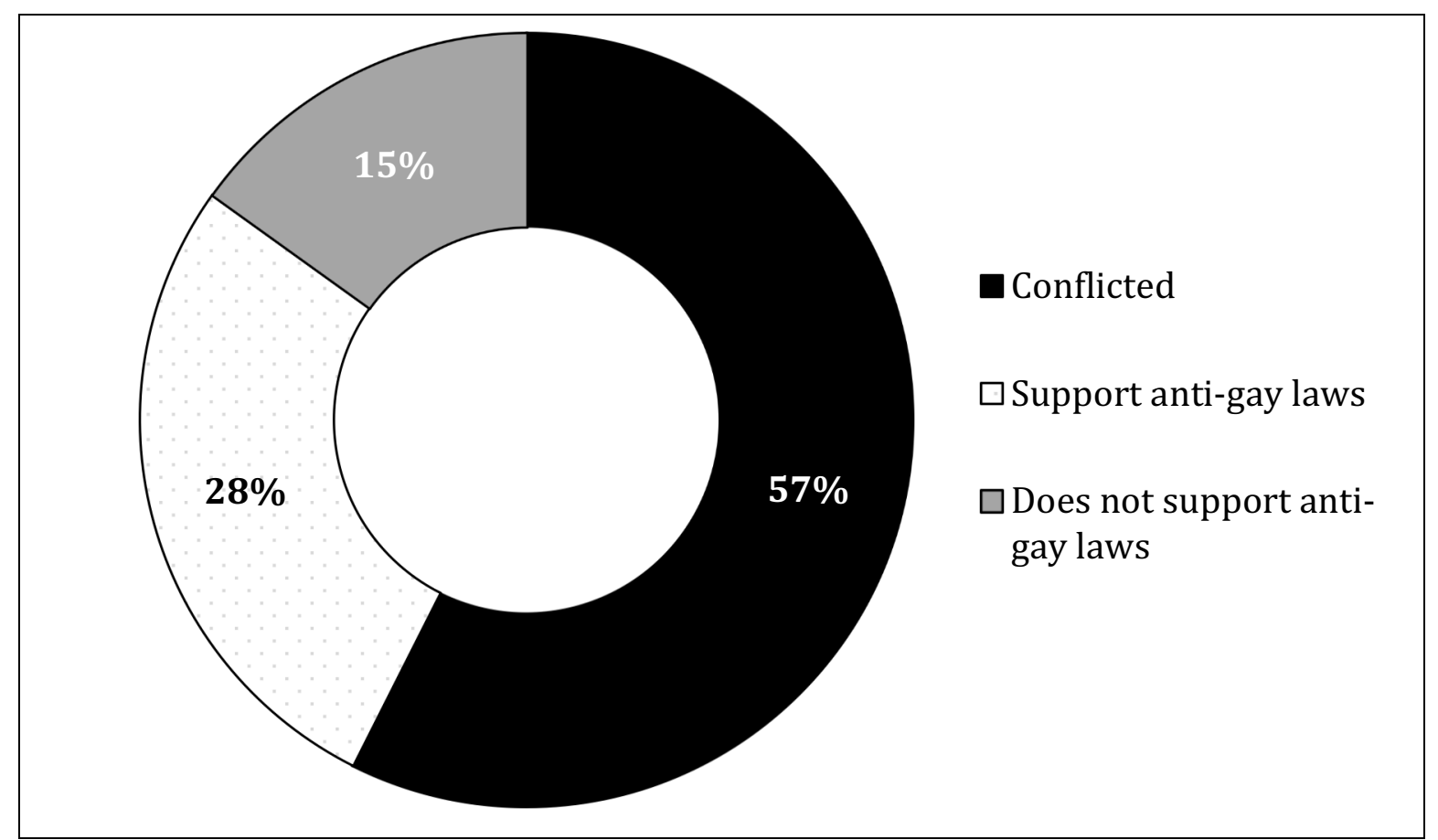

Notes: Sample size: 397. Based on estimation sample 
Figure 3: Interaction effects - The role of competing messages from religion and interpersonal contact on ambivalence and consistent support for the laws

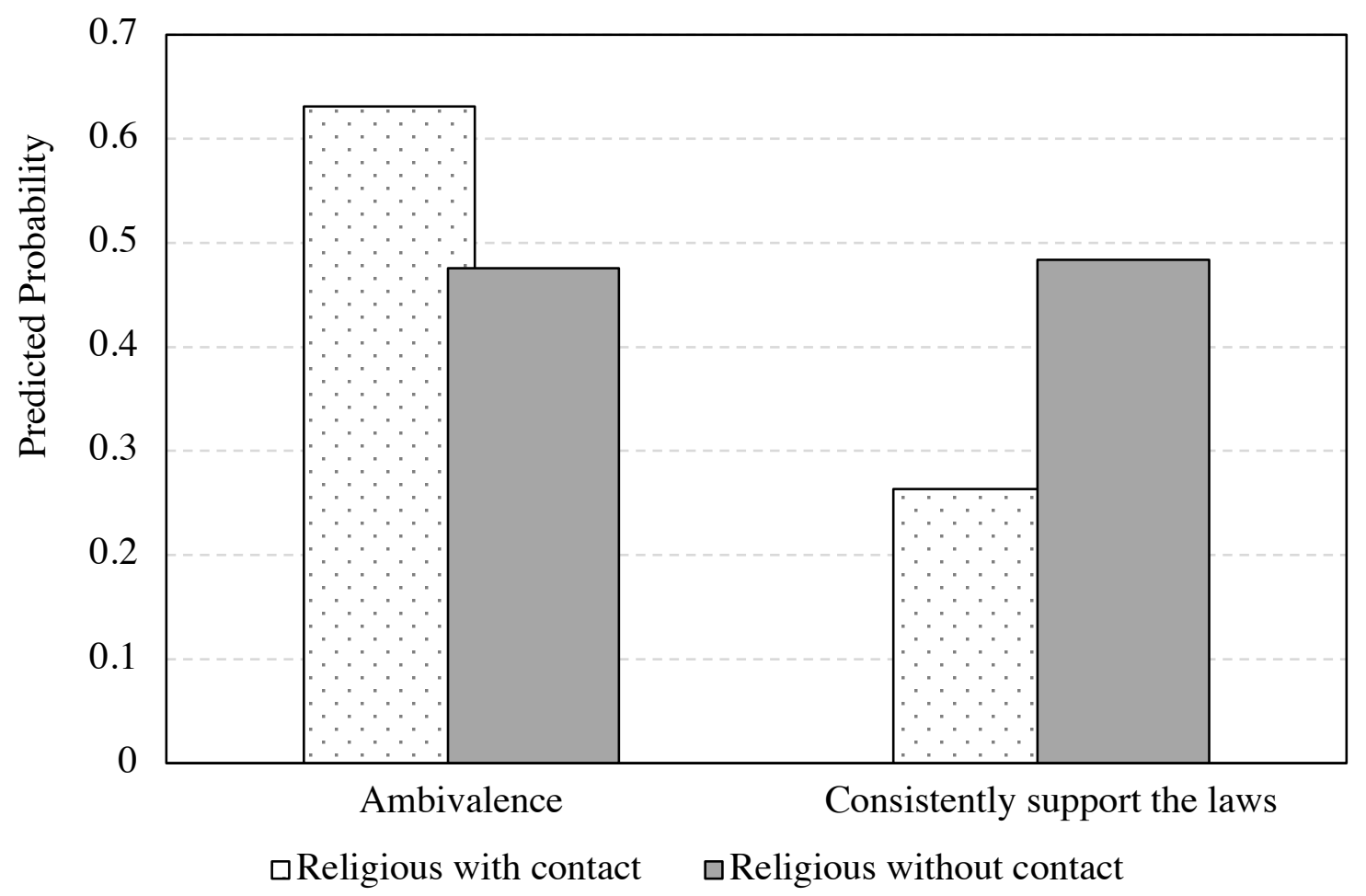

